\title{
An RFID-Based Digital Bracelet for the Timely Assistance of Indigents ${ }^{\dagger}$
}

\author{
Marcela D. Rodríguez *, Alain Diaz-Montes, Carlos G. Verdin, Carlos A. Puga, \\ José M. Ramírez and Ángel G. Andrade \\ Facultad de Ingeniería, Universidad Autónoma de Baja California, 21100 Mexicali, B.C., Mexico; \\ adiaz56@uabc.edu.mx (A.D.-M.); verdinc@uabc.edu.mx (C.G.V.); carlos.puga@uabc.edu.mx (C.A.P.); \\ jramirez53@uabc.edu.mx (J.M.R.); aandrade@uabc.edu.mx (Á.G.A.) \\ * Correspondence: marcerod@uabc.edu.mx; Tel.: +52-686-566-4270 \\ + Presented at the 12th International Conference on Ubiquitous Computing and Ambient Intelligence \\ (UCAmI 2018), Punta Cana, Dominican Republic, 4-7 December 2018.
}

Published: 19 October 2018

\begin{abstract}
High rates of indigence characterize several countries in Latin America, such as Mexico. In the north of our country, the phenomenon of migration contributes to indigence. To get a preliminary understanding of the needs of indigents in our community, we conducted interviews with homeless and migrants. This helped us identify preliminary system requirements that led to the design of a digital bracelet to enable local agencies to monitor and provide support to the indigents who roam the city. We refined our conceptual design through an iterative process of contextual inquiry, persona development, prototyping, and user assessment. An evaluation of our design was conducted with the coordinator of the main social assistance agency of the municipality, which allowed us to confirm the system potential to be used and adopted.
\end{abstract}

Keywords: indigent; migrants; wearable device; usage scenarios

\section{Introduction}

Indigence is defined as living in extreme poverty, lacking the means to feed and dress. According to the Economic Comission for Latin America and the Caribbean (ECLAC) [1], the percentage of the indigent in Latin America in 2012 was 11.3\%, which is equivalent to 66 million people. In Mexico, the percentage of extreme poverty during 2016 was $7.6 \%$, which is equivalent to 8.6 million people [2]. However, the number of homeless in Mexico is difficult to estimate due their lack of home and identification documents [3], in addition to every day, a number of migrants are deported from the United States who stay in northern Mexico, known as the border [4]. Between 85 and 90 percent of the deportations are mainly conducted against Latino men with close affective ties in the United States, [5]. For these reasons, it is understandable that not all those expelled return immediately to their place of origin, but remain living closer to the border to try to cross again or keep close ties with their relatives [3]. However, deportees often face rejection or distrust, as the community refuses and denies them the possibility of being employed, as well as access to certain services. Another factor that contributes to indigence is the existence of border homeless people who are able to cross through official ports of entry using legitimate crossing documents, such as American and Mexican passports, with the aim to take advantage of accessible resources from both countries [4]. For example, resources accessed in Mexico by border homeless people include inexpensive food [4] and opportunities to find a job [6]. Alternatively, many food, clothing and consumer items are cheaper or of better quality on the US side [4]. Therefore, the inhabitants of Mexican cities, institutions and border associations that offer care to migrants have resented this situation [3], and seek to expand their strategies to better support the indigent. For example, in 
Mexicali, our municipality that is on the border, the government will open a permanent shelter in 2019 to provide beds, food and medical care to migrants and homeless people [7].

Our contextual inquiry revealed that indigence is being addressed through a patchwork of specialized services, for example, some civil associations provide meals weekly. However, the roaming that characterizes the indigent makes it difficult to keep them informed in a timely manner about the services offered by the different agencies, such as health campaigns, distribution of hydration packages during the summer and work opportunities. By following an iterative design process of contextual inquiry, scenarios development, prototyping, and system assessment, we have identified requirements that led to the design of a digital bracelet to enable local agencies to monitor and provide support to the indigent-migrants. An evaluation of the design concept with the coordinator of the main service agency allowed us to confirm its potential usefulness and adoption.

In the following section, we present the works related to ours. Section 3 explains the methodology we followed. Section 4 describes the findings of the study conducted to understand the migrant needs. Section 5 explains the conceptual design of our technological solution. Section 6 presents the results of the asessment conducted with an agency coordinator. And Section 7 presents our conclussions and future work.

\section{Related Work}

Different studies have identified that homeless that possess a cell phone, have restrictions to access the Internet and electricity in order to use web-based communication tools or recharge the battery of their devices, respectively [8,9]. For them, entering public places to access such infrastructure, such as bookstores, could have serious consequences [9]. A study conducted in San José California, USA, reveals that $68 \%$ of indigent people possess a cell phone, but only $50 \%$ have internet access services. Taking advantage of this situation, web-based platform was proposed to allow the diversity of organizations available in the area to send SMS messages to announce their services to the homeless who had a cell phone; thus, avoiding the need to have access to the internet [9]. Similarly, in [10], it proposes wearable technology based on QR codes (Quick Response), which are used to configure indigent cell phones to receive different information about services provided by agencies, such as notifications about the schedules to provide food and lodging support, and personalized notifications to remind taking medications. Authors of this work argue that the advantage of separating configuration features from the mobile application that shows the reminding messages, is that if the indigent change or lose their phone, the $\mathrm{QR}$ will allow them to configure a new phone to receive their personalized reminders.

We consider that the previous works restrict the adoption of their proposed applications to the indigents who have a cell phone, which in our context might not always be possible. We conducted the following study to understand what the needs and characteristics of the indigent-migrants are, and to inform the design of a technological solution.

\section{Methodology}

Following the approach of user-centered design [11]; an iteration of this methodology was carried out, which included the following stages as depicted in Figure 1.

\subsection{Contextual Inquiry}

This study was conducted in Mexicali, Mexico, which is a border city with Calexico CA, USA. Through semi-structured interviews, we identified some of the needs of indigent-migrants from our municipality. We contacted migrants who roam in the main public park located in the downtown of the city, which is near the entry port to Calexico, CA, USA. The interview questions focused on issues related to: their purpose to migrate, the support they receive, communication with their families, local socialization and their general needs. Additionally, we also interviewed a coordinator of one of the agencies of the city downtown. As a result, we obtained a set of system requierements. We also used the handwritten notes and photographs taken during the interviews. Individual 
quotes were translated into English for using them in this article. For the qualitative analysis, we followed the thematic analysis approach [12], which consists in searching for potential themes, contrasting the identified themes with the data, and iteratively refining the themes.

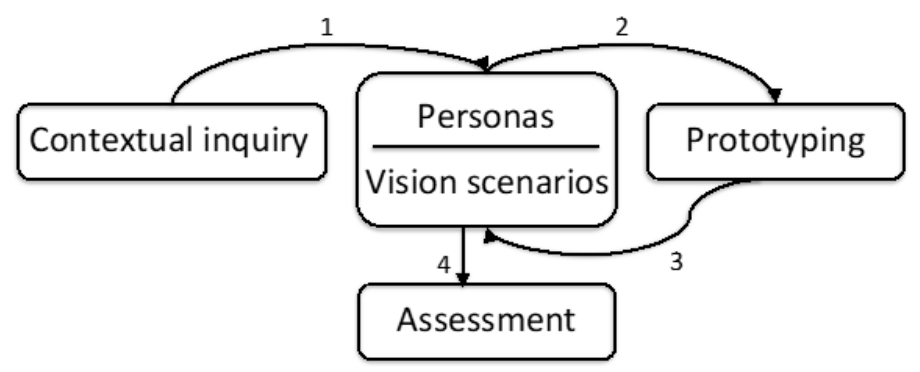

Figure 1. Stages of the followed methodology.

\subsection{Scenario-Based Design}

A scenario is an "informal narrative description of human activities or tasks in a story" [11]. We first designed personas, i.e., scenarios that depict the problem to be addressed which enabled us to decide the specific issues to address through an ambient-based computing solution. Afterwards, we designed vision scenarios that depicted how users will interact with the proposed technology. This technique helped us analyze how technology is (or will be) affecting users' activities, and to communicate our design ideas to a potential user who assess our conceptual design.

\subsection{Prototyping}

We developed a low-fidelity prototype in which we represent how the system will be used, i.e., a conceptual design. To this end, we designed a physical prototype and made video-scenarios to depict the interaction with the users. We also have determined what technology could be appropriate to use to generate an interactive prototype that can be used and evaluated by users.

\subsection{Assessment of the Conceptual Design}

With the purpose of getting feedback about the usefulness of the proposed system, we presented our technological solution to the local Coordinator of the national and public program for social assistance: "Integral Development of the Family", known as DIF [13]. This consisted of a session of approximately one hour and a half, held in the DIF center of the municipality, Mexicali. We presented the results of the context inquiry, and then we explained the proposed technological solution through a vision scenario. Finally, through a set of questions stated at the end of the session, we obtained feedback about the perception of the usefulness of the system for our setting; the adequacy of the system's functionalities; and other desirable functionalities to include in the digital bracelet.

\section{Findings of the Contextual Inquiry}

As shown in Table 1, 6 indigent-migrants participated in the study; half of them reported using cell phones to communicate with their families or social networks, only two participants had relatives in the city and all came from different zones of the country, except 1 that reported having been deported from the United States, and he is waiting for an opportunity to cross the border again. All the participants were migrant men, although this does not mean that there are no indigent women, which was confirmed by the Coordinator of the DIF during the evaluation session, who commented that the majority are men. Next, we report some of the themes that were used to inform the design of our technological proposal. 
Table 1. Participants' characteristics.

\begin{tabular}{cccc}
\hline Subject & Place of Origin & Time Living in Mexicali & Use of com. Technology \\
\hline S1 & Morelia $^{1}$ & 10 months & No \\
S2 & Michoacán $^{1}$ & Several days & No \\
S3 & Sinaloa $^{2}$ & $3-5$ years & Cell phone \\
S4 & Oaxaca $^{1}$ & 3 months & No \\
S5 & Jalisco $^{1}$ (migrant) & 2 months & Cell phone and Facebook \\
S6 & Washington, USA (Deportee migrant) & 3 years & Facebook \\
\hline \multicolumn{4}{r}{}
\end{tabular}

\subsection{Themes}

- The indigents look for job opportunities. However, half of them agreed that they have problems getting a job due to lack of identification documents:

"I need to be busy, I need to work. I am a cook; and a mason's assistant, I'm a good house painter; I am not technician because it is difficult" [S1].

"I worked in stores around the park, but I had problems, for example, in the butcher shop that I helped as a shipper and I had problems [and they fired me]" [S3].

"I need money to go to the United States, so I work 3 or 4 days during the week, I'm always getting a job, but I do not have official documents, so, it is difficult to found a permanent job" [S6].

- Support programs are inflexible. We identified that 3 participants complained about the services offered by the centers and shelters:

"One day, at 8:00 p.m., I went to the shelter [one located in the center] to ask for food, because at that time I assumed they were serving meals, but they did not want to take care of me" [S5].

"At the beginning [when he arrived in Mexicali] I went to a center, but it only served you for 3 days, they [the center personnel] feed us... and we can bathe and sleep there" [S6].

In addition to the complaints of the participants regarding these help centers, subject 2 told us that he did not even know about where these shelters are, and that he would like to obtain information about these supports since he asked us: "Do you have an information brochure?" [S2].

- Mistrust and lack of security. Subject 1 told us that he has several indigent friends who meet in the places they frequent, but at the same time there is distrust when they meet other indigent people, since they have suffered attacks. While subject 5 commented that police officers often abuse them:

"[A few days ago] I was counting the money I had earned [to clean cars], and a police officer saw me, put me in the patrol, and then he took my money" [S5].

\subsection{System Requirements}

Given the answers we obtained from the case study, we concluded that the requirements of the system are:

- Purpose-built. The system should consist of specialized components that offer a set of specific functions to limit the possibility that it could be used for other purposes. What motivates us to propose this requirement is to avoid awakening the interest of the indigent to obtain an economic remuneration trying to sell it.

- Implicit interaction. The system must be easy to understand and use. To reach this aim, its functionality will act as an ambient information system (AIS); it is characterized by presenting relevant information in an unobtrusive way, unless it requires user's attention; additionally, it should enable users to easily monitor the display to obtain the desirable information [14,15]. To 
this end, an AIS uses abstract modalities to represent information, such as pictures, sounds and movement $[14,15]$.

- Timely notifications. Indigents should receive messages alerting them about services availability, such as events where meals will be delivered, health campaigns, and job opportunities.

- Customizable. The system must be flexible enough to allow agencies to communicate to the indigent the diversity of services that they may offer. On the other hand, it should facilitate the sending of personalized messages to meet particular needs of the indigent; for example, sending messages of a job opportunity only to migrants who have particular skills; or a message to communicate information about a health campaign, such as influenza vaccines.

\section{Design}

We designed the HELPi system, a tool for delivering information about assistance services to the indigent. It consists of a portable device that provides notifications about the supports offered by social assistance agencies. It consists of a digital bracelet and a web-based administrator system.

\subsection{Digital Bracelet}

This consists of three elements that define how users will interact with the digital bracelet (see Figure 2):

- Digital pins. We propose that digital pins enable the customization of the services notifications that indigents will receive, i.e., a pin to represent each of the available services, such as health, food delivery, refuge and hydration (see Figure 2a). The corresponding pin lights up when a notification arrives.

- Display screen. It shows simple messages about the place and time when a service will be offered, such as time and location.

- RFID technology. This allows the personalization of the digital bracelet for each indigent-migrant. It will also help to track the assistance services they require and the services they have accessed.

To generate a HELPi conceptual prototype, we made the pins with a 3D printer. To generate a physical and functional prototype, we are considered using the components depicted in Figure 3.

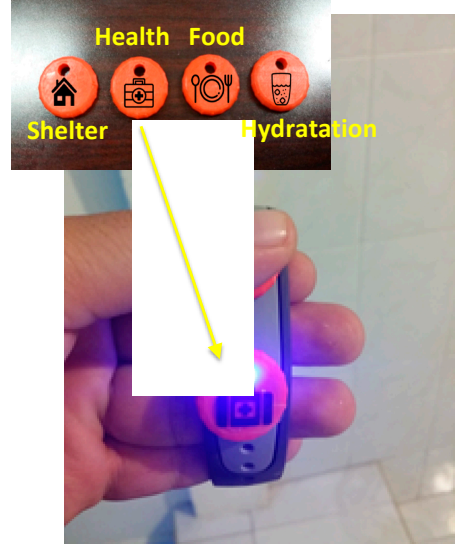

(a)

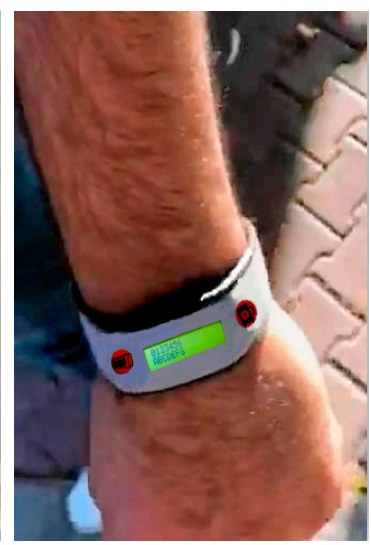

(b)

Figure 2. Digital bracelet prototype: (a) health digital pin highlighted; (b) display showing information about the assistance service. 


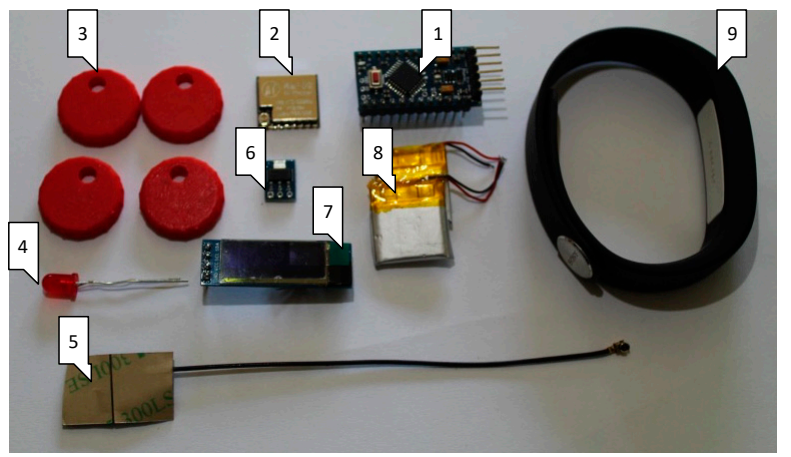

1.- Arduino Pro Mini Microcontroller

2.- RF LoRa module

3.- Pins printed in PLA

4.- LED

5.- Antenna of RF LoRa module

6.- Voltage regulator

7.- OLED Display, $128 \times 32$

8.- Lithium polymer battery

9.- RFID wristband

Figure 3. Components to use for implementing a physical prototype of HELPi digital bracelet.

\subsection{Web-Based Administrator System}

HELPi will have a web-based system to allow agencies' coordinators: (i) to register the migrants (affiliates) who will receive the digital bracelet, (ii) to customize it, and (iii) to configure the delivery of services notifications. For instance, Figure 4a presents the user interface to register information about the migrant origin, arrival date to the municipality. In addition to this, the system allows the agency administrator to configure the type of notification that will be sent to affiliates (Figure $4 b$ ), and specify where the service will be offered, such as place, date, and the time (Figure 4c). Alternatively, the sending of the notification could be repeated to remind the affiliates to access the assistance service.

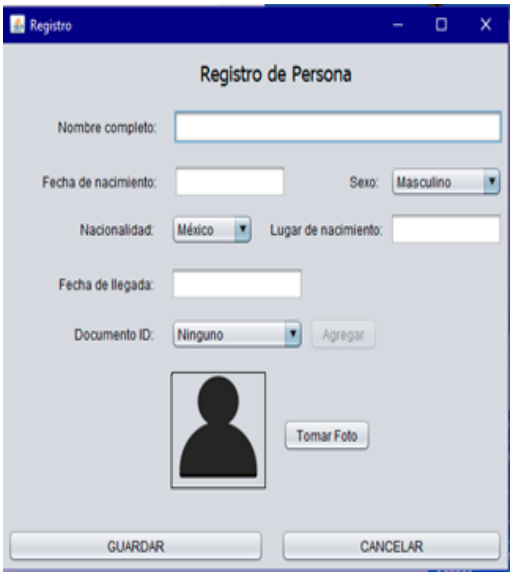

(a)

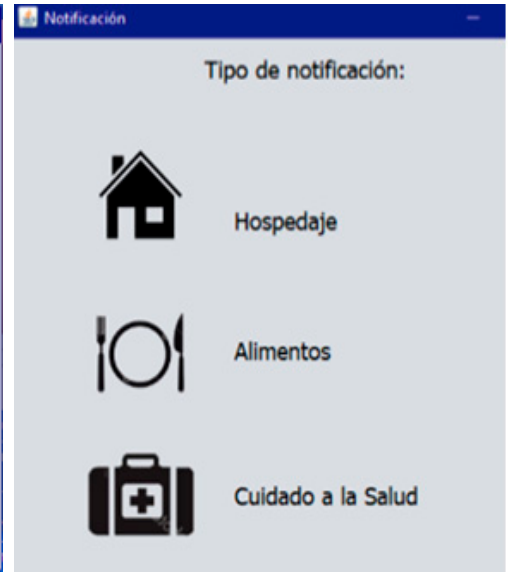

(b)

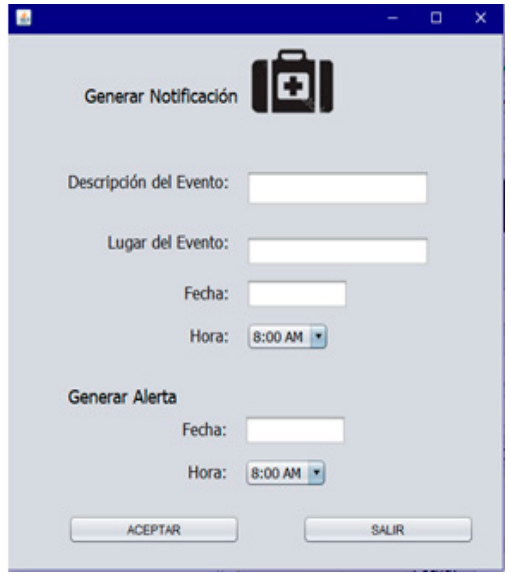

(c)

Figure 4. User interfaces of the HELPi Web-based system to: (a) register migrants; (b) select sending a service notification; (c) configure the notification to send.

\subsection{Usage Scenario}

To describe the HELPi interaction design, the following scenario is presented: "Luis is the coordinator of the Center for the Integral Development of the Family (DIF). Given the high summer temperatures in Mexicali, Luis receives a donation that includes water and electrolytes to be delivered to low-income people, so he decides to send a notification to all the affiliates to his agency. He accesses the web-based system, and selects to send a health notification through the user interface presented in Figure 4b. Then, using the user interface of Figure 4c, he specifies that this support will be distributed at El Cachanilla Park from July 11 to 15, from 4:00 a.m. to 6:00 p.m. Upon finding Juan, at that moment in the city downtown, he noticed that the health pin (Figure 3a) is on, and reads on the screen (Figure $3 b$ ) that the delivery will be in one of the parks close his current location. As Juan is ready to pick up his pantry, then he arrives at the park and the DIF support group asks him to show his bracelet. The DIF assistant brings a mobile device to Juan's bracelet to scan his RFID code, which allows him to register that Juan received the support". 


\section{Evaluation of the Conceptual Design of HELPi}

From the session with the DIF coordinator, explained in Section 3.4, we obtained feedback that helped us identify the perception of utility and interest in adopting it, which resulted in:

The coordinator of the DIF confirmed that the system seemed appropriate. Additionally, she provided information about the problem that will be addressed. For example, she said:

"Currently, migrants do not have a secure way of knowing about the places in which food will be offered at specific times, or about available shelters and health services".

She also commented that the DIF shelter opens only at certain times of the year; and that DIF weekly offers food in certain parks of the city; while other agencies cover other indigent-migrants needs. With the above-mentioned, she confirmed that our system would help to publicize the availability of the services offered by the different associations of the municipality, which may change based on the season of the year. In addition, she questioned aspects related to the system adoption. In particular, she asked questions that showed us her interest in knowing the functionality of the system, so that it could be used in the real context. For example, she asked about the cost and who would manage it; she also showed concern for some security aspects, such as the risk of stealing the bracelet and that the homeless information associated to the bracelet could be misused.

\section{Conclusions and Future Work}

We believe that the proposed design would help improve access to the services offered in the community. We plan to extend the assessment of the conceptual design by including 2-3 agencies' coordinators. This will enable us to get a better understanding of its feasibility to be adopted. Afterwards, we plan to implement a physical prototype with the components depicted in Figure 3, and evaluate its usability with migrants.

Funding: This work was supported in part by the National Council of Science and Technology (CONACyT, Mexico) through ‘Fondo Sectorial de Investigación para la Educación' under Grant 288670-Y.

Acknowledgments: We thank to the participants of the study and the DIF coordinator of Mexicali.

Conflicts of Interest: The authors declare no conflict of interest.

\section{References}

1. Inclusive Social Development: He Next Generation of Policies for Overcoming Poverty and Reducing Inequality in Latin America and the Caribbean. Cepal Report. Available online: https://www.cepal.org/en (accessed on 17 June 2018).

2. Measuring Poverty. CONEVAL Report. Available online: https://www.coneval.org.mx (accessed on 17 June 2018).

3. Albicker, S.L.; Velasco, L. Deportación y estigma en la frontera México-Estados Unidos: Atrapados en Tijuana. Norteamérica 2016, 11, 99-129, doi:10.20999/nam.2016.a004.

4. Campbell, H.; Lachica, J.G. Transnational Homelessness: Finding a Place on the US-Mexico Border. J. Borderl. Stud. 2013, 28, 279-290, doi:10.1080/08865655.2013.863441.

5. Golash-Boza, T.; Hondagneu-Sotelo, P. Latino Immigrant Men and the Deportation Crisis: A Gendered Racial Removal Program. Latino Stud. 2013, 11, 271-292, doi:10.1057/lst.2013.14.

6. Collins, K. Life in the US-Mexican Border Region: Residents' Perceptions of the Place. J. Borderl. Stud. 2013, 28, 127-146, doi:10.1080/08865655.2013.796210.

7. Tendrá Mexicali Albergue Permanente Para Migrantes. La Cronica Newspaper. Available online: http://www.lacronica.com/EdicionEnLinea/Notas/Noticias/23032018/1320490-Tendra-Mexicali-alberguepermanente-para-migrantes.html (accessed on 23 March 2018).

8. Woelfer, J.P.; Hendry, D.G. Homeless young people and living with personal digital artifacts. In Proceedings of the SIGCHI Conference on Human Factors in Computing Systems (CHI'11), Vancouver, BC, Canada, 7-12 May 2011; ACM: New York, NY, USA, 2011; pp. 1697-1706. 
9. Figueira, S.; Linnell, N.; Fong, N. Street Connect: SMS announcements for homeless people. In Proceedings of the IEEE Global Humanitarian Technology Conference (GHTC), San Jose, CA, USA, 20-23 October 2013; IEEE: Piscataway, NJ, USA, 2013; pp. 495-500.

10. Aljadaan, A.; Bihani, K.; Gebrekristos, M. QR-Codes for the Chronically Homeless. In Proceedings of the CHI ‘08 Extended Abstracts on Human Factors in Computing Systems (CHI EA'08), Florence, Italy, 5-10 April 2008; ACM: New York, NY, USA, 2008; pp. 3879-3884.

11. Rosson, M.B.; Carroll, J.M. Usability Engineering: Scenario-Based Development of Human-Computer Interaction; Morgan Kaufmann Publishers Inc.: San Francisco, CA, USA, 2002; pp. 15-23, ISBN 1-55860-712-9.

12. Braun, V.; Clarke, V. Using thematic analysis in psychology. Qual. Res. Psychol. 2006, 3, 77-101.

13. National System for the Integral Development of the Family (DIF). Available online: https://www.gob.mx/inea/documentos/sistema-nacional-para-el-desarrollo-integral-de-la-familia-dif (accessed on 17 June 2018).

14. Pousman, Z.; Stasko, J. A taxonomy of ambient information systems: Four patterns of design. In Proceedings of the ACM Working Conference on Advanced Visual Interfaces, Venezia, Italy, 23-26 May 2006; ACM: New York, NY, USA, 2006; pp. 67-74.

15. Mankoff, J.; Dey, A.D.; Hsie, G. Heuristic evaluation of ambient displays. In Proceedings of the SIGCHI Conference on Human Factors in Computing Systems (CHI'03), Fort Lauderdale, FL, USA, 5-10 April 2003; ACM: New York, NY, USA, 2003; pp. 169-176.

(C) 2018 by the authors. Licensee MDPI, Basel, Switzerland. This article is an open access article distributed under the terms and conditions of the Creative Commons Attribution (CC BY) license (http://creativecommons.org/licenses/by/4.0/). 